\title{
Maintenance and recov- ery characteristics after sevoflurane or propofol during ambulatory surgery in children with epidural blockade
}

Beverley C. Guard BM MRCP FRCA, Nancy Sikich BSCN RN, Jerrold Lerman BASC MD FRCPC FANZCA, Mark Levine MB FRCPC

Purpose: To compare the maintenance and recovery characteristics after sevoflurane with those after propofol in children with epidural blockade.

Methods: Fifty unpremedicated, children ASA I-II, 2 - 8 yr of age, scheduled for elective urological surgery as outpatients, were randomly allocated to receive either: I) sevoflurane for induction and maintenance of anaesthesia or 2) propofol for induction (2-3 mg.kg- iv) and for maintenance $\left(5-10 \mathrm{mg}^{-1} \mathrm{~kg}^{-1} \cdot \mathrm{hr}^{-1} \mathrm{iv}\right.$ ). All children received $\mathrm{N}_{2} \mathrm{O} 70 \%$ in oxygen before induction and throughout the anaesthetic, rocuronium for neuromuscular blockade and a lumbar or caudal epidural block before incision. Heart rate (HR), systolic blood pressure (SBP), recovery times and all side effects during maintenance and recovery were recorded by a blinded observer. Adverse events during the first 24 hr were also recorded.

Results: Mean HR increased 5-10\% after induction in both groups reaching a maximum by five minutes. Heart rate returned to baseline by skin incision in the sevoflurane group and by $10 \mathrm{~min}$ after induction in the propofol group. During maintenance, HR decreased by $10-20 \%$ below baseline values by $20 \mathrm{~min}$ in the propofol group only, where it remained for the remainder of the anaesthetic. Similarly, SBP increased by $10 \%$ after induction of anaesthesia in both groups, but returned to baseline by $10 \mathrm{~min}$. Light anaesthesia occurred in four $(16 \%)$ children, all in the propofol group. Emergence and recovery indices were similar in the two groups.

Discussion: Sevoflurane and propofol exhibit similar maintenance and recovery profiles when combined with epidural analgesia in children undergoing ambulatory surgery.

Objectif : Comparer les caractéristiques du maintien et de la récupération de l'anesthésie après l'administration de sévoflurane avec celles de l'anesthésie après le propofol chez des enfants qui ont subi un blocage péridural.

Méthode : Cinquante enfants ASA I-II, âgés de 2 à 8 ans, qui n'ont reçu aucune prémédication, devaient subir une chirurgie urologique élective ambulatoire et ont été répartis au hasard pour recevoir soit : I) du sévoflurane pour l'induction et le maintien de l'anesthésie, ou 2) du propofol pour l'induction (2-3 $\mathrm{mg}^{-1} \mathrm{~kg}^{-1}$ iv) et le maintien (5-10 $\mathrm{mg} \cdot \mathrm{kg}^{-1} \cdot \mathrm{hr}^{-1}$ iv). Tous les enfants ont reçu un mélange de $\mathrm{N}_{2} \mathrm{O} 70 \%$ et d'oxygène avant l'induction et tout au long de l'anesthésie, du rocuronium pour le blocage neuromusculaire et une anesthésie péridurale lombaire ou caudale avant l'incision. La fréquence cardiaque (FC), la tension artérielle systolique (TAS), le moment de la récupération et tous les effets secondaires pendant le maintien et la récupération de l'anesthésie ont été enregistrés par un observateur impartial. On a aussi noté les événements indésirables pendant les 24 premières $\mathrm{h}$.

Résultats : La FC moyenne a augmenté de 5-10\% après l'induction de l'anesthésie dans les deux groupes et a atteint sa valeur maximale en cinq minutes. Elle est revenue à sa valeur de base lors de l'incision cutanée dans le groupe sévoflurane et en dix minutes après l'induction dans le groupe propofol. Pendant le maintien de l'anesthésie, la FC a diminué de 10-20\% sous sa valeur de base en 20 min dans le groupe propofol seulement et elle est demeurée ainsi pour le reste de l'anesthésie. De même, la TAS a augmenté de $10 \%$ après l'induction de l'anesthésie dans les deux groupes, mais est revenue à sa valeur de base en 10 minutes. Une anesthésie légère s'est produite chez quatre $(16 \%)$ des enfants du groupe propofol. Les indices de réveil et de récupération ont été similaires dans les deux groupes.

Conclusion : Le sévoflurane et le propofol présentent des profils de maintien et de récupération similaires quand ils sont combinés à l'analgésie péridurale chez des enfants devant subir une chirurgie ambulatoire.

From the Department of Anaesthesia and the Research Institute, The Hospital for Sick Children, University of Toronto, 555 University Avenue, Toronto, Ontario, Canada M5G IX8.

Address correspondence to: Dr. J. Lerman, Fax: 416-813-7543; E-mail: lerman@anaes.sickkids.on.ca

Supported in part, by a grant from Abbott Laboratories Limited, Montreal, Quebec, Canada. Presented in part at the annual meeting of the Canadian Anaesthetists' Society, June 1997.

Accepted for Publication August 13, 1998 
$\mathrm{B}$

OTH sevoflurane and propofol possess qualities that are desirable for infants and children who require ambulatory surgery under general anaesthesia. Studies in children have confirmed the excellent induction characteristics, haemodynamic stability and rapid emergence and recovery qualities for both anaesthetics when compared with halothane. ${ }^{1-10}$ However, the maintenance and recovery characteristics of sevoflurane and propofol have not been compared directly with one another and not in children in whom general anaesthesia was supplemented with an epidural block. Accordingly, we designed the following randomized, single blinded study in healthy children undergoing urological surgery as outpatients.

\section{Methods and materials}

After approval by the institutional Ethics Committee, written consent was obtained from the parents of 50 children. All children were ASA I-II, two to eight years of age, fasted, unpremedicated and scheduled for urological surgery as outpatients. The children were randomly assigned to receive either sevoflurane or propofol for induction and maintenance of anaesthesia. Randomization was achieved using random number tables prepared in advance of commencing the study.

A complete medical history and physical examination including baseline heart rate, systolic blood pressure (measured non-invasively) and temperature were obtained preoperatively.

Immediately before induction of anaesthesia, noninvasive monitors including an electrocardiogram, pulse oximeter and blood pressure cuff were applied. Seventy percent nitrous oxide in a balance of oxygen was then administered to all children via face mask for up to one minute before establishing $i v$ access and then throughout the maintenance of anaesthesia. For children in the sevoflurane group, anaesthesia was induced using stepwise increases in the inspired concentration of sevoflurane ( $2 \%$ increments every two breaths to a maximum inspired concentration of $8 \%$ ). Intravenous access was established when the eyelash reflex was lost. For children in the propofol group, anaesthesia was induced with $2-3 \mathrm{mg} \cdot \mathrm{kg}^{-1}$ propofol $i v$. Tracheal intubation was facilitated by $0.5-0.8 \mathrm{mg} \cdot \mathrm{kg}^{-1} i v$ rocuronium in both groups. After intubation, ventilation was controlled mechanically via a Mapleson $F$ (Jackson-Rees modification of the Ayre's T-piece) breathing circuit to maintain end-tidal $\mathrm{P}_{\mathrm{ET}} \mathrm{CO}_{2}$ between 35 and $45 \mathrm{mmHg}$. For children in the sevoflurane group, anaesthesia was maintained with an end-tidal sevoflurane concentration of $2.5 \%$. The sevoflurane concentration was analyzed via a calibrated Datex Capnomac airway gas monitor
(Helsinki, Finland). For children in the propofol group, anaesthesia was maintained with a continuous propofol infusion of $10 \mathrm{mg} \cdot \mathrm{kg}^{-1} \cdot \mathrm{hr}^{-1}$, that was decreased to 7.5 $\mathrm{mg} \cdot \mathrm{kg}^{-1} \cdot \mathrm{hr}^{-1}$ after $30 \mathrm{~min}$. The infusion of propofol could be decreased to $5 \mathrm{mg} \cdot \mathrm{kg}^{-1} \cdot \mathrm{hr}^{-1}$ after another 30 $\mathrm{min}$ provided there were no signs of light anaesthesia. Light anaesthesia, defined as a HR or BP $>120 \%$ of baseline, was managed by increasing the end-tidal sevoflurane concentration in $0.5 \mathrm{MAC}$ increments during sevoflurane anaesthesia and by infusing a bolus of propofol $1.5 \mathrm{mg} \cdot \mathrm{kg}^{-1}$ followed by an increase in the infusion rate of $2.5 \mathrm{mg} \cdot \mathrm{kg}^{-1} \cdot \mathrm{hr}^{-1}$ during propofol anaesthesia. In both groups, neuromuscular blockade was maintained during anaesthesia with $0.3-0.5 \mathrm{mg} \cdot \mathrm{kg}^{-1}$ rocuronium iv as required. Before surgical incision, a lumbar or caudal epidural block was established in all children using 0.5 to $1.0 \mathrm{mg} \cdot \mathrm{kg}^{-1}$ bupivacaine $0.175 \%$ without epinephrine. An epidural catheter was inserted where possible. Supplemental bupivacaine $0.175 \%$ without epinephrine was administered as required for analgesia. At the conclusion of surgery, neuromuscular blockade was antagonized with $0.04 \mathrm{mg} \cdot \mathrm{kg}^{-1}$ neostigmine and $0.02 \mathrm{mg} \cdot \mathrm{kg}^{-1}$ atropine. Both the study drug and $\mathrm{N}_{2} \mathrm{O}$ were discontinued simultaneously and the trachea was extubated when the gag reflex had returned, ventilation was spontaneous and regular, and movement of the extremities was purposeful.

Heart rate (HR), systemic systolic blood pressure (SBP), haemoglobin oxygen saturation $\left(\mathrm{sPO}_{2}\right)$, tem-

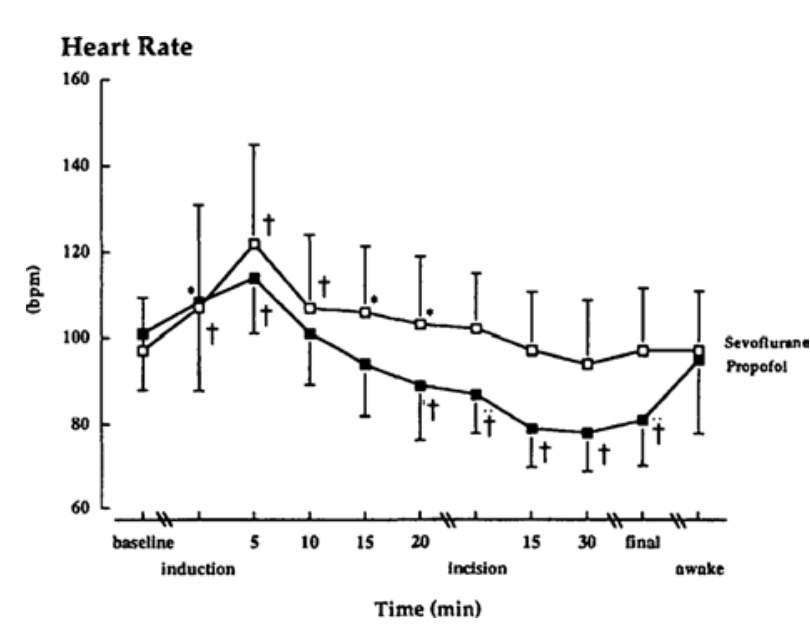

FIGURE 1 Heart rate (mean \pm sd) responses during sevoflurane and propofol anaesthesia. ${ }^{*} P<0.05$ and $\dagger P<0.01$ compared to their respective baseline values. During maintenance (defined as the period from five minutes after induction until the "final" measurements), heart rate in the sevoflurane group exceeded that in the propofol group at all times except $10 \mathrm{~min}$ after induction $(P<$ 0.001 ) (between group comparisons are not shown for clarity). 


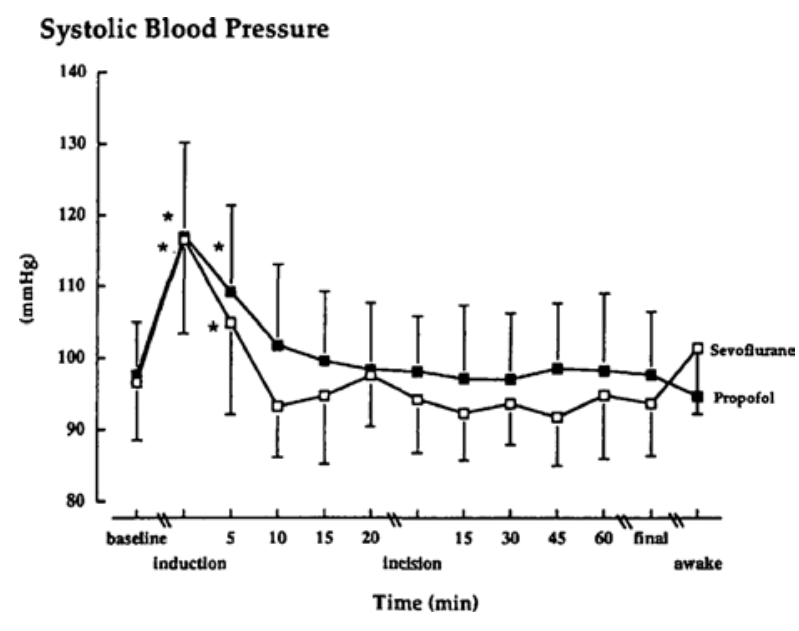

FIGURE 2 Systolic blood pressure (mean $\pm \mathrm{sd}$ ) responses during sevoflurane and propofol anacsthesia. $\dagger P<0.01$ compared with respective baseline values. Blood pressure did not differ between the two treatments at any time.

perature and end-tidal gas concentrations were recorded on arrival in the operating room, at induction of anaesthesia and every five minutes thereafter until skin incision, one minute after skin incision and then every $15 \mathrm{~min}$ until skin closure. The intervals from initiation of the study drug (sevoflurane or propofol) until skin incision (incision) and until discontinuation of the anaesthetic (duration of anaesthesia) and the interval from discontinuation of the anaesthetic until extubation (time to extubation) were recorded. Light anaesthesia was defined as a $H R$ or SBP $>120 \%$ of baseline. Light anaesthesia was treated with an increase in end-tidal sevoflurane concentration in the sevoflurane group or a bolus and an increase in the infusion rate of propofol in the propofol group.

During postoperative recovery, vital signs and the modified Aldrete score were assessed every $10 \mathrm{~min}$ for one hour or until eligible for discharge from the recovery room. Discomfort at the site of surgery was managed with epidural bupivacaine $0.175 \%$ without epinephrine. In those children without an epidural catheter, discomfort in the recovery room was managed with $20 \mathrm{mg} \cdot \mathrm{kg}^{-1}$ rectal acetaminophen and if pain persisted, $0.05 \mathrm{mg} \cdot \mathrm{kg}^{-1}$ iv morphine. The time intervals from discontinuation of the anaesthetic to spontaneous eye-opening (time to emergence), response to age-appropriate commands, orientation to time, place and person (age-appropriate), attaining a modified Aldrete score 8 , and discharge from hospital were recorded by a research nurse who was blinded to

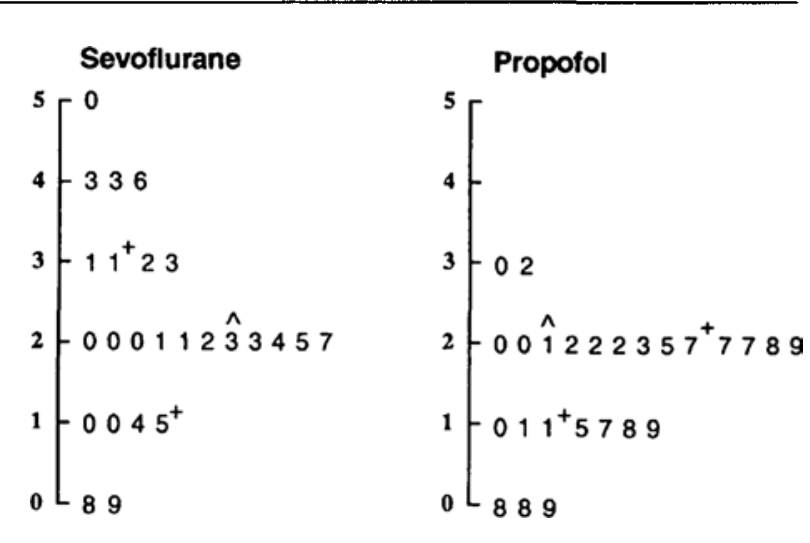

FIGURE 3 Stem and leaf plots of the time to reach an Aldrete score 8 in the 25 children in each of the sevoflurane and propofol groups. The numbers to the left of the $\mathrm{Y}$-axis in bold (stem) are the first digits of the time and those to the right of the $\mathrm{Y}$-axis (leaf) are the second digits. Combined, these two digits are the time to reach an Aldrete score 8 for each child. (For example, recovery times at 30 and $32 \mathrm{~min}$ in the propofol group are plotted across from the stem numbers (on the $\mathrm{Y}$-axis) of 3 and are identified as the leaf values, 0 and 2 under the Propofol heading). The median value, ${ }^{\wedge}$, and the 25 th and 75 th percentiles as,,+ are indicared.

the anaesthetic assignment. All adverse events during emergence (including airway reflex responses, secretions, excitation, rigidity, hemoglobin oxygen desaturation and vomiting) and recovery (pain and vomiting) until discharge from hospital were recorded. Time to eligibility for discharge from the hospital was recorded. On the day after surgery, the childrens' parents were interviewed by phone to assess the quality of recovery and to determine the presence of adverse events (i.e., nausea, vomiting, pain and prolonged sedation).

\section{Statistics}

Sample size was estimated using the time to eligibility for discharge from the recovery room (defined as a modified Aldrete score of 8 ). We assumed that a clinically relevant difference in the time to discharge from recovery between the two treatments was ten minutes. Using a two-tailed alpha value of 0.05 , a $B$ of $15 \%$, a standard deviation in the time to discharge of $10 \mathrm{~min}$ and a drop-out rate of $10 \%, 25$ patients were required in each treatment group. ${ }^{11}$

Demographic data were compared using an unpaired Bonferroni $t$ test. Analysis of HR and BP data was performed using two-way ANOVA with repeated measures. Significant main and interaction effects were determined for both between and within group mea- 
TABLE I Demographic data

\begin{tabular}{lll}
\hline & Sevoflurane & Propofol \\
\hline No. of patients & 25 & 25 \\
Age (yr) & $4.6 \pm 1.8$ & $4.2 \pm 1.8$ \\
Weight (kg) & $17.7 \pm 4.9$ & $17.7 \pm 5.0$ \\
Sex & & \\
$\quad$ male & $23(92 \%)$ & $22(88 \%)$ \\
$\quad$ female & $2(8 \%)$ & $3(12 \%)$ \\
Duration of anacsthesia (min) & $83.6 \pm 44.9$ & $88.6 \pm 44.5$ \\
Duration of surgery (min) & $58.4 \pm 41.2$ & $63.0 \pm 42.3$ \\
Type of surgery & & \\
$\quad$ penile surgery & $9(36 \%)$ & $11(44 \%)$ \\
$\quad$ hernia/hydrocoele & $15(60 \%)$ & $8(32 \%)$ \\
$\quad$ orchidopexy & $1(4 \%)$ & $6(24 \%)$ \\
$\quad$ hypospadias \& hernia & $2(8 \%)$ & 0 \\
\hline
\end{tabular}

Means \pm sd unless indicated

* number of children (percent)

TABLE II Maintenance and Emergence Side Effects

\begin{tabular}{lll}
\hline & Sevoflurane & Propofol \\
\hline $\begin{array}{l}\text { Maintenance: } \\
\text { signs of light anaesthesia* }\end{array}$ & $0(0)$ & $4(16)$ \\
$\begin{array}{l}\text { Emcrgence: } \\
\text { breath holding }\end{array}$ & $3(12)$ & $2(8)$ \\
coughing & $11(44)$ & $12(48)$ \\
laryngospasm & $2(8)$ & 0 \\
bronchospasm & 0 & 0 \\
secretions & $8(32)$ & $9(36)$ \\
excitation & $2(8)$ & $1(4)$ \\
rigidity / shivering & $1(4)$ & $1(4)$ \\
SpO $<90 \%$ & 0 & 0 \\
$\quad$ vomiting & $2(8)$ & 0 \\
Recovery: & & \\
Pain requiring morphine & $7(28)$ & $3(12)$ \\
Vomiting-before discharge & $3(12)$ & $1(4)$ \\
$\quad$ - in first 24 hr postop & $7(28)$ & $6(24)$ \\
\hline
\end{tabular}

Data are the number of children (percent)

* HR or SBP > $120 \%$ of baseline

More than one event may have been experienced by a child

surements using the Student-Newman-Keuls tests. ${ }^{12}$ Differences between means for continuous data are presented as $95 \%$ confidence intervals. Ordinal data were compared using the Mann Whitney U test. Nominal data (i.c., the proportions of children exhibiting signs of light anaesthesia (HR or BP $>120 \%$ baseline), those experiencing adverse events postoperatively and those reaching an Aldrete score 8) were compared using Fisher's Exact test. The mean times to an Aldrete score 8 for the 25 children in each group were displayed graphically using a stem and leaf plot. ${ }^{13}$ Data are presented as means \pm sd except where indicated. The level of significance was accepted as 0.05 .
TABLE III Emergence and Recovery Times*

\begin{tabular}{|c|c|c|c|c|}
\hline & Sevoflurane & Propofol & $\begin{array}{l}95 \% \mathrm{C} \\
\text { lower }\end{array}$ & $\begin{array}{l}\text { CIt } \\
\text { upper }\end{array}$ \\
\hline Extubation & $7.8 \pm 2.2$ & $6.7 \pm 2.8$ & -0.3 & 2.5 \\
\hline Eye opening & $18.1 \pm 8.1$ & $14.5 \pm 9.2$ & -1.3 & 8.5 \\
\hline \multicolumn{5}{|l|}{ Response to verbal } \\
\hline Aldrete score 8 & $24.9 \pm 11.6$ & $20.0 \pm 7.3$ & -0.7 & 10.3 \\
\hline Orientation & $26.8 \pm 10.1$ & $24.8 \pm 8.5$ & -3.3 & 7.3 \\
\hline Oral fluids & $67.2 \pm 33.5$ & $71.1 \pm 36.1$ & -23.7 & 15.9 \\
\hline \multicolumn{5}{|l|}{ Recovery room } \\
\hline Hospital dischargeł & $134 \pm 41$ & $131 \pm 41$ & -25.8 & 24.4 \\
\hline
\end{tabular}

* All times are reported in minutes (mean $\pm \mathrm{SD}$ ), referenecd to the discontinuation of anaesthesia

† $95 \%$ confidence intervals (CI) for the difference between sevoflurane and propofol

$\ddagger \mathrm{n}=22$ for sevoflurane and $\mathrm{n}=21$ for propofol

\section{Results}

Demographic data, including the duration of anaesthesia and surgery and the type of surgery performed, were similar for the two treatment groups (Table I). The infusion rate of propofol was between 5 and 10 $\mu \mathrm{g} \cdot \mathrm{kg}^{-1} \cdot \mathrm{hr}^{-1}$ for all children.

\section{Maintenance of Anaesthesia}

HEART RATE: Mean HR increased after induction of anaesthesia in both groups, reaching a maximum measured value at five minutes (Figure 1). Heart rate returned to baseline by skin incision in the sevoflurane group and by $10 \mathrm{~min}$ after induction in the propofol group. Although HR remained unchanged from baseline for the duration of the anaesthetic in the sevoflurane group, it decreased below baseline by $20 \mathrm{~min}$ in the propofol group $(P<0.01)$ where it remained for the duration of the anaesthetic. Heart rate did not change in response to surgical incision in either group. During maintenance, defined as the period from five minutes after induction until the discontinuation of anaesthesia ("final" measurement in Figure 1), the $\mathrm{HR}$ in the sevoflurane group exceeded that in the propofol group $(P<0.001)$ at all times except $10 \mathrm{~min}$ after induction.

Systolic BloOd Pressure: Mean SBP increased after induction of anaesthesia in both groups $(P<$ 0.01) compared with baseline, but returned to baseline by $10 \mathrm{~min}$. Systolic blood pressure did not change in response to skin incision in either group. Systolic blood pressure was similar to baseline for the remainder of the maintenance period in both groups.

None of the children in the sevoflurane group and four $(16 \%)$ children in the propofol group showed evi- 
dence of light anaesthesia during the maintenance period (Table II). The mean ( $\pm \mathrm{sd}$ ) propofol infusion rate during maintenance of anaesthesia was $9.0 \pm 0.94$ $\mathrm{mg} \cdot \mathrm{kg}^{-1} \cdot \mathrm{hr}^{-1}$, and at the end of surgery was $6.6 \pm 1.8$ $\mathrm{mg} \cdot \mathrm{kg}^{-1} \cdot \mathrm{hr}^{-1}$. The mean infusion rate of propofol during the periods of light anaesthesia was similar to the infusion rate in the absence of light anaesthesia.

Epidural analgesia was established in all but one child. For this child, an ilio-inguinal field block was performed by the surgeon before incision and the child was included in the analysis. Opioids were not administered intraoperatively to any child.

\section{Emergence and Recovery from Anaesthesia}

The emergence and recovery times were similar in the sevoflurane and propofol groups (Table III). Recovery milestones, including a modified Aldrete score of 8 (Figure 3) were also similar in the two groups (Table III). The stem and leaf plots of the time to reach an Aldrete score 8 (Figure 3 ) display a tally of the observations as well as the distribution of times for the 25 children in each treatment. The coefficients of variation in the times to reach an Aldrete score 8 were $46.6 \%$ for sevoflurane and $36.5 \%$ for propofol. Six children (three in each group) remained in hospital overnight for surgical indications. The times to hospital discharge in the remaining 44 children did not differ between the two groups (Table III).

Side effects during emergence from anaesthesia were similar in the two groups (Table II). All studyrelated side effects were considered to be mild or moderate in intensity by the investigators. In the recovery room, intravenous morphine was administered to $28 \%$ of the children in the sevoflurane group and to $12 \%$ in the propofol group. The incidences of vomiting before discharge from hospital in the sevoflurane group, $12 \%$, and in the propofol group, $4 \%$, were similar.

There were no major events reported by the parents during the first $24 \mathrm{hr}$ after surgery in either group. The incidence of vomiting after discharge from hospital in the sevoflurane group (28\%) was similar to that in the propofol group (24\%). The percent of children or parents who would request the same anaesthetic again was $82 \%$ in the sevoflurane group and $100 \%$ in the propofol group.

\section{Discussion}

The purpose of this study was to compare the maintenance and recovery characteristics of sevoflurane or propofol in children undergoing ambulatory surgery. We compared these two particular anaesthetics because both are commonly used in children in ambu- latory surgery. Our results indicate that the maintenance and recovery characteristics after sevoflurane and propofol are similar in children who have epidural blockade. Furthermore, our results are consistent with two published studies in which sevoflurane and propofol were compared during ambulatory surgery in adults. ${ }^{14,15}$

The transient increase in HR post-induction of anaesthesia with sevoflurane in this study, although modest in magnitude, is consistent with two published reports. ${ }^{14}$ The aetiology of this $25 \%$ increase in HR, although unclear at present, is more likely to be physiological rather than pharmacological in origin. We hold this view this because anticholinergic drugs were not administered to any of the children in these studies. Several physiological responses could account for the transient increase in HR during sevoflurane anaesthesia including a chemoreceptor triggered response, direct sympathetic nervous system activation and light anaesthesia. Central sympathetic activation is an unlikely cause of the increase in HR since sevoflurane anaesthesia in adults does not trigger sympathetic discharge. ${ }^{16}$ Until further data are available, these HR responses will remain an interesting curiosity.

During the maintenance period, the haemodynamic responses to sevoflurane and propofol anaesthesia were similar except in two minor respects. First, the mean HR exceeded the baseline measurement for longer during sevoflurane anaesthesia than it did during propofol anaesthesia. Second, the mean HR in the propofol group decreased $20 \%$ below baseline at 20 min after induction where it remained for the remainder of the anaesthetic. Neither of these findings necessitated any intervention.

Although propofol has been used for maintenance of anaesthesia in children, slow heart rates have been neither common nor problematic. ${ }^{17,18}$ Nonetheless, in several studies in which propofol was used together with a regional block as the maintenance anaesthetic, HR decreased either before skin incision or after incision. ${ }^{14,19}$ In the present study, the combination of propofol, rocuronium and epidural blockade may have contributed in whole or in part to the slower HR in the propofol group compared with the sevoflurane group. Although it is tempting to attribute the slow HR in the propofol group to the dose of propofol used, there is no known relationship between the dose of propofol and decreases in HR in either children or adults. ${ }^{14,15,17,19,20}$

One of the difficulties in designing a study in which an inhaled anaesthetic is compared with an intravenous agent is to ensure that the depth of anaesthesia for the two anaesthetics remains similar. Where 
both anaesthetics are inhalational agents, this can be achieved readily by administering similar MAC-multiples of the anaesthetics. In this study however, where one anaesthetic is an inhaled agent and the other is an intravenous agent, there is no common clinical measure or instrument to gauge comparable depths of anaesthesia in children. In the absence of such an objective measure, we relied upon the haemodynamic responses to the anaesthetic and titrated the drug doses to maintain the HR and SBP to within $20 \%$ of baseline values. On the basis of the similar incidence of light anaesthesia observed, we believe that the doses of the two anaesthetics used were equivalent (Table II). Further studies are required to determine whether haemodynamic responses are valid tools to gauge the depth of anaesthesia when either of these anaesthetics is used in the presence of an epidural block.

We found that the mean recovery times after sevoflurane were similar to those after propofol. This is consistent with two previous studies in adults. ${ }^{14,15}$ Although the mean times to reach an Aldrete score of 8 were similar, the stem and leaf plots suggested that the rate of recovery after sevoflurane may be more variable than that after propofol (Figure 3). Further studies are required to determine whether this observation is valid.

We designed this study to detect a clinically significant difference of $10 \mathrm{~min}$ in the time to eligibility for discharge from the recovery room (modified Aldrete score of 8 ) with a power of $85 \%$ between sevoflurane and propofol. However, we found a difference of only $0.7 \mathrm{~min}$ in the discharge time which was not statistically significant. This small difference prevented us from rejecting the null hypothesis. Yet, we cannot conclude that the two anaesthetics are equivalent in terms of discharge time because the $95 \%$ CI for the difference (Table III) exceeded the clinically significant difference of $10 \mathrm{~min}$ that was used to estimate the sample size. ${ }^{21}$ These results, which are consistent with those reported previously in adults, ${ }^{14,15}$ suggest that the speed and quality of emergence and recovery after sevoflurane and propofol are similar, but not necessarily equivalent, in healthy children with epidural blockade.

The incidence of postoperative pain that required opioid treatment, $28 \%$ in the sevoflurane group and $12 \%$ in the propofol group, is consistent with published reports. ${ }^{22,23}$ In adults, postoperative morphine requirements after sevoflurane or propofol anaesthesia were similar, ${ }^{15}$ although analgesia was required sooner after sevoflurane than after propofol. In the present study, there was a trend towards more pain during the first 24 postoperative $\mathrm{hr}$ after sevoflurane compared with propofol, but these data were based on the par- ents' subjective responses. Further data are required to determine whether postoperative analgesic requirements after sevoflurane and propofol differ in children with epidural blockade.

Postoperative vomiting is not uncommon after urological surgery, particularly in children. ${ }^{24}$ Several studies have shown that propofol decreases the incidence of postoperative vomiting compared with other anaesthetic techniques. ${ }^{8,25}$ However, when the incidence of vomiting after sevoflurane and propofol was compared in adults, ${ }^{14,15}$ the results were inconsistent. In one study, the incidence of vomiting after the two anaesthetics was similar ${ }^{14}$ whereas in the second study, the incidence after sevoflurane was three-fold greater than that after propofol. ${ }^{15}$ Methodological differences between these two studies may account in part, for the inconsistent results. In the present study, the incidence of postoperative vomiting during the first $24 \mathrm{hr}$ was similar, albeit small. The relatively small incidence of postoperative vomiting in this study may be attributed to the avoidance of gastric inflation before tracheal intubation, the opioid-sparing action of the epidural blocks and the postanaesthetic policy of elective oral fluid administration. ${ }^{26}$

In summary, the results of this study demonstrated that the maintenance and recovery characteristics after sevoflurane and propofol are similar when these drugs are used in combination with epidural analgesia in healthy children. The rapid recovery times and low incidence of perioperative side effects suggest that both anaesthetics are suitable for ambulatory urological surgery in children.

\section{Acknowledgments}

We thank our surgical colleagues in the Division of Urology for their co-operation in conducting this study.

\section{References}

1 Kawana S, Wachi J, Nakayama $M$, Namiki A. Comparison of haemodynamic changes induced by sevoflurane and halothane in paediatric patients. Can J Anaesth $1995 ; 42$ : 603-7.

2 Lerman J, Sikich $N$, Kleinman S, Yentis $S$. The pharmacology of sevoflurane in infants and children. Anesthesiology 1994; 80: 814-24.

3 Sarner JB, Levine $M$, Davis PJ, Lerman J, Cook DR, Motoyama EK. Clinical characteristics of sevoflurane in children. A comparison with halothane. Anesthesiology 1995; 82: 38-46.

4 Piat $V$, Dubois $M-C$, Johanet $S$, Murat I. Induction and recovery characteristics and hemodynamic responses to sevoflurane and halothane in children. Anesth Analg 1994; 79: 840-4. 
5 Sury MRJ, Black A, Hemington L, Howard R, Hatch DJ, Mackersie A. A comparison of the recovery characteristics of sevoflurane and halothane in children. Anaesthesia 1996; 51: 543-6.

6 Lerman J, Davis PJ, Welborn LG, et al. Induction, recovery, and safety characteristics of sevoflurane in children undergoing ambulatory surgery.

Anesthesiology 1996; 84: 1332-40.

7 Borgeat A, Popovic V, Meier D, Schwander D. Comparison of propofol and thiopental/halothane for short-duration ENT surgical procedures in children. Anesth Analg 1990; 71: 511-5.

8 Martin TM, Nicolson SC, Bargas MS. Propofol anesthesia reduces emesis and airway obstruction in pediatric outpatients. Anesth Analg 1993; 76: 144-8.

9 Hannallah RS, Britton JT, Schafer PG, Patel RI, Norden JM. Propofol anaesthesia in paediatric ambulatory patients: a comparison with thiopentone and halothane. Can J Anaesth 1994; 41: 12-8.

10 Schröter J, Motsch J, Hufnagel AR, Bach A, Martin E. Recovery of psychomotor function following general anaesthesia in children: a comparison of propofol and thiopentone/halothane. Paediatr Anaesth 1996; 6: 317-24.

11 Cohen J. Statistical Power Analysis for the Behavioral Sciences, 2nd ed. Hillsdale, New Jersey: Lawrence Erlbaum Associates, 1988: 52-60.

12 STATISTICA $^{2}$ for the Macintosh. Tulsa, Statsoft, Inc., 1994.

13 Dawson-Saunders B, Trapp RG. Basic \& Clinical Biostatistics, 2nd ed. Norwalk, Conn: Appleton \& Lange, 1994: 24-5.

14 Fredman B, Nathanson $M H$, Smith I, Wang J, Klein $K$, White PF. Sevoflurane for outpatient anesthesia: a comparison with propofol. Anesth Analg 1995; 81: 823-8.

15 Jellish WS, Lien CA, Fontenot HJ, Hall R. The comparative effects of sevoflurane versus propofol in the induction and maintenance of anesthesia in adult patients. Anesth Analg 1996; 82: 479-85.

16 Ebert T], Muzi M, Lopatka $C W$. Neurocirculatory responses to sevoflurane in humans. A comparison to desflurane. Anesthesiology 1995; 83: 88-95.

17 Doyle E, McFadzean W, Morton NS. IV anaesthesia with propofol using a target-controlled infusion system: comparison with inhalation anaesthesia for general surgical procedures in children. Br J Anaesth 1993; 70: 542-5.

18 Murray DJ, Oyos TL, Forbes RB, Disterboft $M$, Maboney $L T$. Hemodynamic depression during propofol infusions in children. Anesthesiology 1993; 79: Al157.

19 Herregods L, Rolly G, Versichelen L, Rosseel MT. Propofol combined with nitrous oxide-oxygen for induction and maintenance of anaesthesia. Anaesthesia 1987; 42: 360-5.
20 Morton NS, Jobnston G, White M, Marsh BJ. Propofol in paediatric anaesthesia. Paediatr Anaesth 1992; 2: 89-97.

21 Jones $B$, Jarvis $P$, Lewis JA, Ebbutt $A F$. Trials to assess equivalence: the importance of rigorous methods. BMJ 1996; 313: 36-9.

22 Fell D, Derrington MC, Taylor E, Wandless JG. Paediatric postoperative analgesia. A comparison between caudal block and wound infiltration of local anaesthetic. Anaesthesia 1988; 43: 107-10.

23 Bramwell RGB, Bullen C, Radford P. Caudal block for postoperative analgesia in children. Anaesthesia 1982; 37: 1024-8.

24 Lerman J. Surgical and patient factors involved in postoperative nausea and vomiting. $\mathrm{Br} J$ Anaesth 1992; 69(Suppl 1): 24S-32.

25 Weir PM, Munro HM, Reynolds PI, Lewis IH, Wilton NCT. Propofol infusion and the incidence of emesis in pediatric outpatient strabismus surgery. Anesth Analg $1993 ; 76: 760-4$.

26 Schreiner MS, Triebwasser A, Keon TP. Ingestion of liquids compared with preoperative fasting in pediatric outpatients. Anesthesiology 1990; 72: 593-7. 